\title{
Electrochemical Methods for Quantitative Estimation of Ambroxol Hydrochloride in drug for the Treatment of Asthmatic Bronchitis
}

\author{
Lina $\mathrm{Li}$ \\ Medical School, Xuchang University, Xuchang, 461000 China \\ E-mail: LinaLi02@hotmail.com, lilina7188@163.com
}

Received: 17 April 2021/ Accepted: 28 June 2021 / Published: 10 August 2021

\begin{abstract}
This study presented the electrochemical quantitative estimation of ambroxol hydrochloride (AHC) as drug safety for asthmatic bronchitis on $\mathrm{ZnO}$ nanoparticles electrodeposited on carboxylated CNTs modified glassy carbon electrode (ZnO NPs/c-CNTs/GCE). The electrodeposition technique was applied for the preparation of the $\mathrm{ZnO}$ NPs/c-CNTs/GCE. The structural and morphological analyses using FESEM and XRD showed ZnO NPs in hexagonal wurtzite crystal structure electrodeposited on the twisted and wrapped tubular structure of c-CNTs. The electrochemical study using the CV technique showed that ZnO NPs/c-CNTs/GCE indicated lower peak potential, higher sensitivity and stability than c-CNTs/GCE and ZnO NPs/GCE due to the synergetic effect of ZnO NPs and c-CNTs. The studies of interference and concentration effects using DPV technique showed to the selective response of $\mathrm{ZnO}$ NPs/c-CNTs/GCE to the electrochemical determination of AHC, and the linear range, sensitivity and detection limit were obtained 1 to $120 \mu \mathrm{M}, 10.7393 \mu \mathrm{A} / \mu \mathrm{M}$ and $0.02 \mu \mathrm{M}$, respectively. The practical ability of ZnO NPs/SWCNTs modified GCE was investigated for the determination of AHC content in ambroxol hydrochloride syrup as a real sample. The results evidenced to good precision and appropriate validity for practical analyses in pharmaceutical samples.
\end{abstract}

Keywords: Ambroxol hydrochloride; Differential pulse voltammetry; Carboxylated CNTs; ZnO nanoparticles; Electrodeposition

\section{$\underline{\text { FULL TEXT }}$}

(C) 2021 The Authors. Published by ESG (www.electrochemsci.org). This article is an open access article distributed under the terms and conditions of the Creative Commons Attribution license (http://creativecommons.org/licenses/by/4.0/). 